\title{
Oxirane-2,2-dicarboxamides: synthesis, reactions and biological activity
}

Victor V. Dotsenko ${ }^{\mathrm{a}, \mathrm{b} *}$, Yulia E. Aniskina ${ }^{\mathrm{a}}$, Vladimir D. Strelkov ${ }^{\mathrm{a}, \mathrm{c}}$, Lyudmila V. Dyadyuchenko ${ }^{\mathrm{c}}$, Gennady D. Krapivin ${ }^{\mathrm{d}}$

${ }^{a}$ Kuban State University, 149 Stavropolskaya Str., Krasnodar 350040, Russian Federation

${ }^{b}$ ChemEx Lab, Vladimir Dal' Lugansk National University, Lugansk, 91034 Russian Federation

${ }^{c}$ All-Russian Research Institute of Biological Plant Protection, Laboratory of plant growth regulators, 350039 Krasnodar, Russian Federation

${ }^{d}$ Kuban State Technological University, 2 Moskovskaya st., 350072 Krasnodar, Russian Federation

Abstract: The mild Radziszewski oxidation of 3-aryl-2-cyanoacrylamides with $\mathrm{H}_{2} \mathrm{O}_{2}-\mathrm{NaOH}$ (or $\mathrm{H}_{2} \mathrm{O}_{2}-\mathrm{Na}_{2} \mathrm{CO}_{3}$ ) system leads to the formation of oxirane-2,2dicarboxamides in good yields. The reactions and structure of the obtained products were studied. The aminolysis of the oxirane-2,2-dicarboxamides effected by primary amines occurs in keeping with Krasusky rule to afford 2-(1-R-aminoethyl)-3-aryl-2-hydroxymalonamides or tartronamide. We found that 3-(4methoxyphenyl)oxirane-2,2-dicarboxamide exhibited moderate activity both as plant growth regulator and 2,4-D antidote.

Keywords: Radziszewski oxidation, oxiranes, aminolysis, beta-amino alcohols, tartronamide, biological activity.

Oxiranes belong to a practically important class of compounds with a broad spectrum of biological activity [1]. Our interests have been focused on the compouns with oxirane-2-carboxamide (glicydamide) fragment. Among such compounds were found highly active agents such as antifungal antibiotic cerulenin 1, an inhibitor of cysteine peptidase E64 2, a natural fungicide and bactericide (-)flavipucin 3, etc.<smiles>C/C=C/C/C=C/CCC(=O)[C@@H]1O[C@H]1C(N)=O</smiles>

One of the earliest methods to obtain oxirane-2-carboxamides is based on the Darzens reaction of $\alpha$-halogen amides and carbonyl compounds. However, this 
approach is inconvenient, requires special conditions and often gives low yields. A more promising approach is based on the modified Radzishevsky-Payne reaction the oxidative hydrolysis of unsaturated nitriles with $\mathrm{H}_{2} \mathrm{O}_{2}$ under alkaline conditions $[2,3]$. However, despite the availability of the starting reactants and oxidants, mild reaction conditions and its high selectivity, the method is not widely represented in the literature [1,4]. For our studies, we have selected (E)-3-aryl-2cyanoacrylamides as a good starting point to oxirane-2-carboxamides. The starting (E)-3-aryl-2-cyanoacrylamides $\mathbf{4}$ and $\mathbf{5}$ were prepared by Knoevenagel reaction according to the known methods [4]:<smiles>[Y7]C=C(C)C(=O)NC[Y7]</smiles>

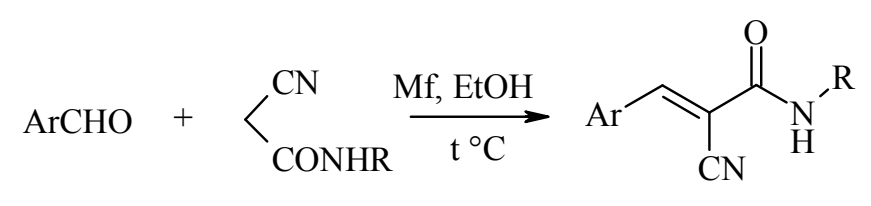

$\mathrm{R}=\mathrm{H} ; \mathrm{CH}_{2} \mathrm{Ph} ; \mathrm{Ph}$.

We found that compounds $\mathbf{4}$ and $\mathbf{5}$ could be readily oxidized by the action of $32 \% \mathrm{H}_{2} \mathrm{O}_{2}$ and $10 \% \mathrm{NaOH}$ (or $10 \% \mathrm{Na}_{2} \mathrm{CO}_{3}$ ) in EtOH to afford amides 6 and 7. The reaction is stereoselective: the products have the same configuration as the starting acrylonitriles $\mathbf{4}$ and $\mathbf{5}$. The reaction proceeds through the formation of peroxycarbiminic acids $\mathbf{8}$, following by the intramolecular oxidation to form oxirane-2-carboxamides.

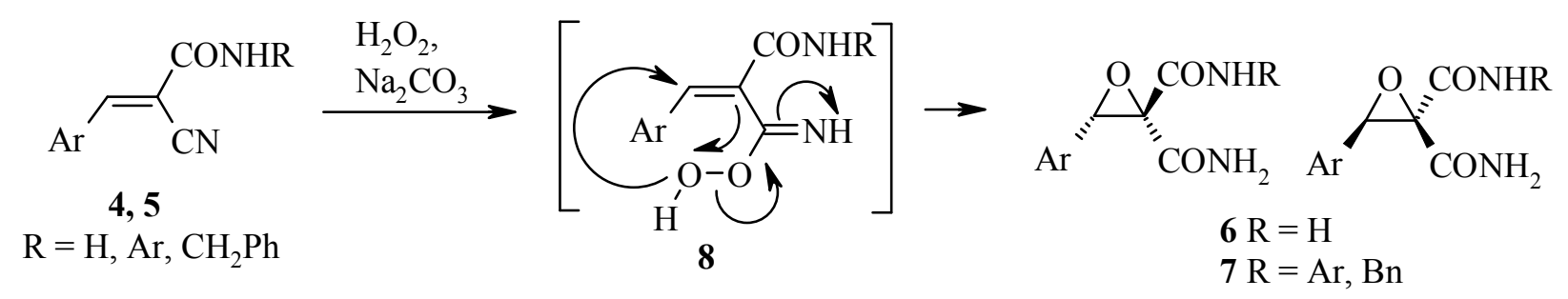

Sodium carbonate, which reacts with $\mathrm{H}_{2} \mathrm{O}_{2}$ to form in situ the so-called sodium sesquipercarbonate $2 \mathrm{Na}_{2} \mathrm{CO}_{3} \times 3 \mathrm{H}_{2} \mathrm{O}_{2}$, was found to be as effective oxidant as the system alkali- $\mathrm{H}_{2} \mathrm{O}_{2}$. We failed to obtain oxirane-2-carboxamides bearing 4(dimethylamino)phenyl and 2-furyl substituents at C-3 position. On the one hand, this is presumably due to the strong donating effect of $\mathrm{Me}_{2} \mathrm{~N}$ that makes the corresponding acrylamides $\mathbf{4}$ and $\mathbf{5}$ unreactive towards the nucleophilic attack of $\mathrm{HOO}^{-}$, and on the other - due to easy oxidation of furyl fragment under Radzishevsky conditions. The structure of compounds $\mathbf{6}$ and 7 was confirmed by spectral methods, including 2D NMR (Fig. 1 and 2). 


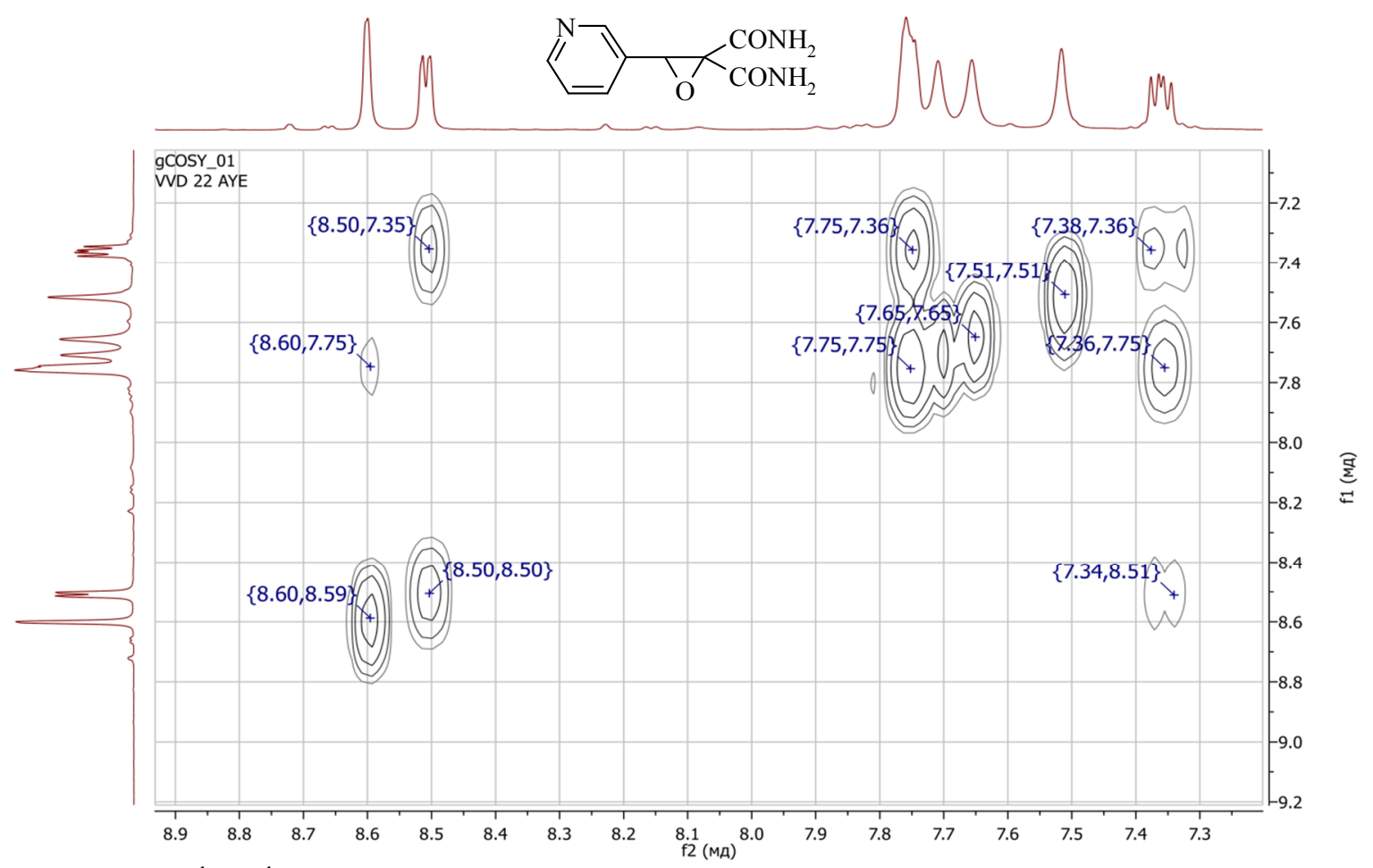

Fig. 1. NMR ${ }^{1} \mathrm{H}-{ }^{1} \mathrm{H}$ COSY spectrum (400 MHz, DMSO-d $\mathrm{d}_{6}$ ) of 3-(pyridin-3yl)oxirane-2,2-dicarboxamide (fragment)

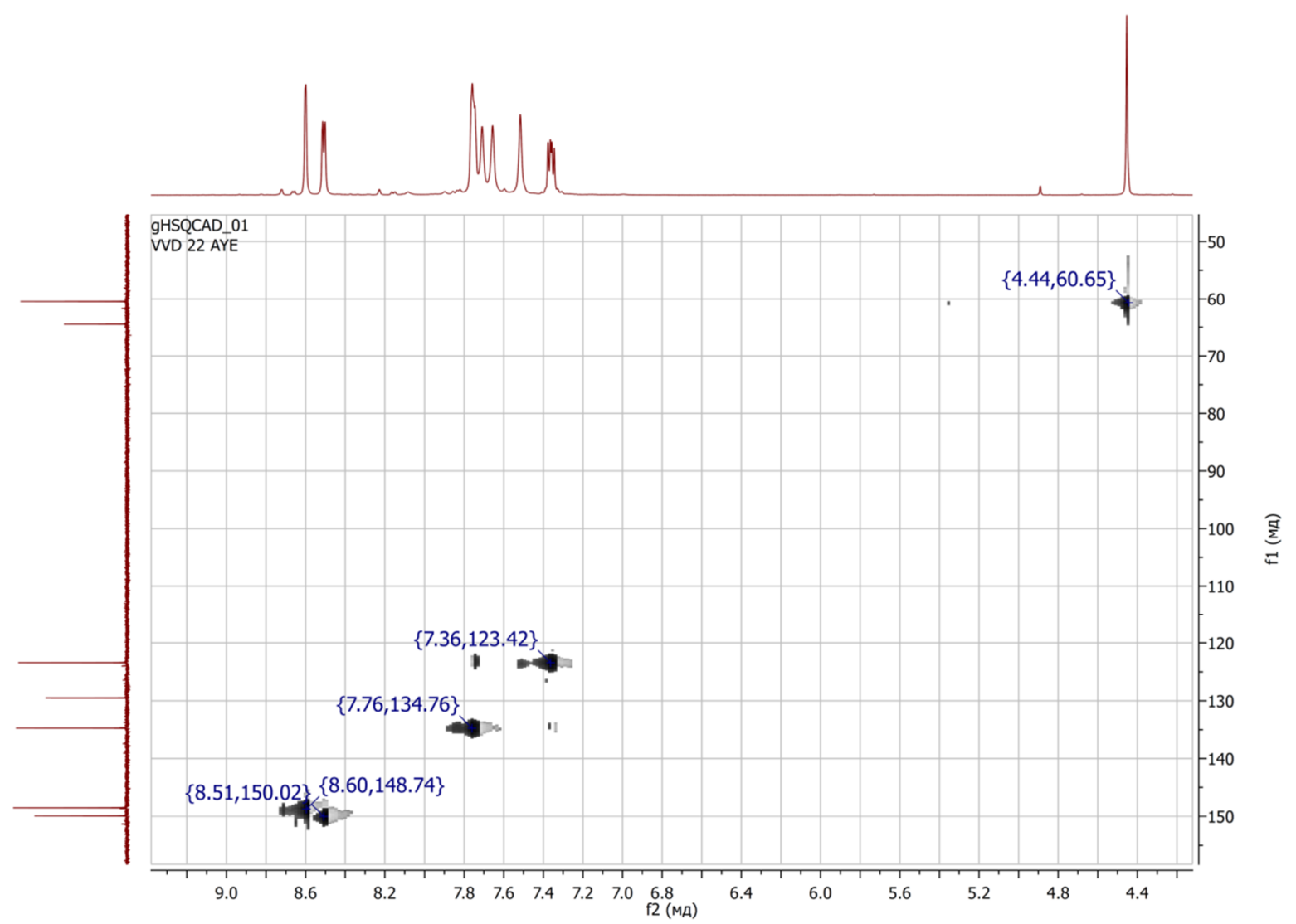

Fig. 2. NMR ${ }^{1} \mathrm{H}-{ }^{13} \mathrm{C}$ HSQC spectrum (100/400 MHz, DMSO-d ${ }_{6}$ ) of 3-(pyridin-3yl)oxirane-2,2-dicarboxamide 
We have studied some compounds $\mathbf{6}$ for growth regulating activity on sunflower seedlings, as well as antidotes towards 2,4-D. The results for one of the most active compound 6a $\left(\mathrm{Ar}=4-\mathrm{MeOC}_{6} \mathrm{H}_{4}, \mathrm{R}=\mathrm{H}\right)$ are shown in Tables 1 and 2 .

Table 1. The test results for $\mathbf{6 a}$ as plant growth regulators

\begin{tabular}{|c|c|c|c|c|c|c|c|c|c|c|}
\hline \multirow{3}{*}{ Compound } & \multirow{3}{*}{$\begin{array}{c}\text { Estimated } \\
\text { by }\end{array}$} & \multirow{3}{*}{$\begin{array}{c}\begin{array}{c}\text { Control } \\
\text { group }\end{array} \\
\text { A }\end{array}$} & \multicolumn{8}{|c|}{ Concentration of the compound, $\%$} \\
\hline & & & \multicolumn{2}{|c|}{$10^{-2}$} & \multicolumn{2}{|c|}{$10^{-3}$} & \multicolumn{2}{|c|}{$10^{-4}$} & \multicolumn{2}{|c|}{$10^{-5}$} \\
\hline & & & A & B & A & B & A & B & A & B \\
\hline & $\begin{array}{l}\text { length of } \\
\text { hypocotyl }\end{array}$ & 84 & 89 & 106 & 104 & 124 & 95 & 113 & 93 & 110 \\
\hline $6 a$ & $\begin{array}{l}\text { length of } \\
\text { root }\end{array}$ & 158 & 155 & 98 & 172 & 109 & 174 & 110 & 155 & 98 \\
\hline
\end{tabular}

A - hypocotyl length, mm

B - hypocotyl length in \% with respect to A.

Table 2. The test results for $\mathbf{6 a}$ as 2,4-D antidote on sunflower seedlings

\begin{tabular}{|c|c|c|c|c|c|c|c|c|c|c|c|c|}
\hline \multirow{3}{*}{ Compound } & \multirow[t]{3}{*}{ Estimated by } & \multirow{3}{*}{$\begin{array}{c}\text { Control } \\
\text { group }\end{array}$} & \multirow{2}{*}{\multicolumn{2}{|c|}{$\begin{array}{l}\text { Herbicide } \\
\text { (reference) }\end{array}$}} & \multicolumn{8}{|c|}{ Concentration of the compound, $\%$} \\
\hline & & & & & \multicolumn{2}{|c|}{$10^{-2}$} & \multicolumn{2}{|c|}{$10^{-3}$} & \multicolumn{2}{|c|}{$10^{-4}$} & \multicolumn{2}{|c|}{$10^{-5}$} \\
\hline & & & $\mathrm{A}$ & $\mathrm{C}$ & $\mathrm{A}$ & $\mathrm{B}$ & A & $\mathrm{B}$ & A & $\mathrm{B}$ & $\mathrm{A}$ & $\mathrm{B}$ \\
\hline \multirow{2}{*}{$\mathbf{6 a}$} & $\begin{array}{l}\text { length of } \\
\text { hypocotyl }\end{array}$ & 85 & 48 & 44 & 53 & 110 & 44 & 92 & 44 & 92 & 42 & 88 \\
\hline & $\begin{array}{l}\text { length of } \\
\text { root }\end{array}$ & 157 & 60 & 62 & 67 & 112 & 54 & 90 & 63 & 105 & 53 & 88 \\
\hline
\end{tabular}

A - hypocotyl length, $\mathrm{mm}$

B - hypocotyl length in \% with respect to A.

Thus, the compound 6a shows good growth regulating activity and modest antidotal effect to 2,4-D in the sunflower seedlings tests.

Next, we examined the reactivity of obtained compounds towards primary amines, and have studied the structure of the ammonolysis products. The reaction was carried out by refluxing equimolar amounts of an oxirane and a primary amine in ethanol. It was found that the ring opening occurs regioselectively (though not stereoselectively) according to the Krasusky rule, and resulted in the formation of expected $\beta$-amino- $\alpha$-hydroxide-carboxamides 9.

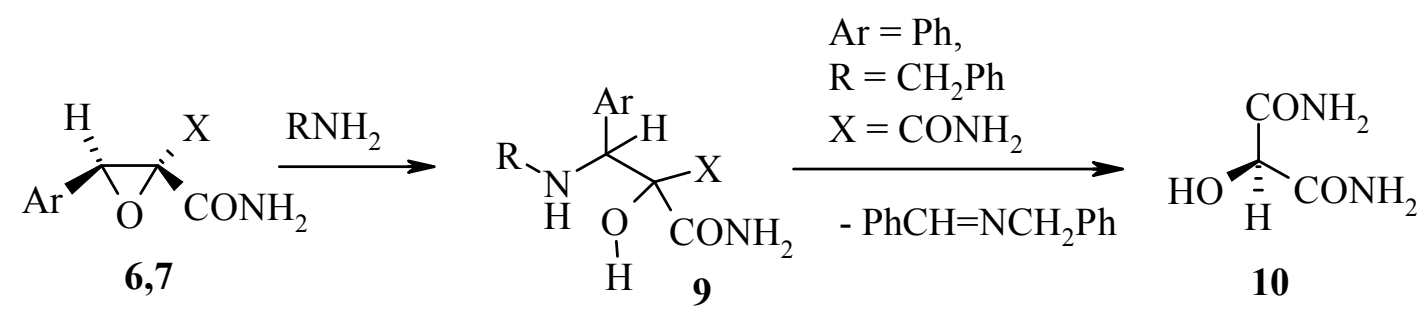


In one case, the final product was recognized as tartronamide $\mathbf{1 0}$ formed as the secondary product by the elimination of azomethyne from $\mathbf{9}$. The selected results are shown in Table 3.

Table 3. The structure of the products of reaction of oxiranes 6,7 with amines.

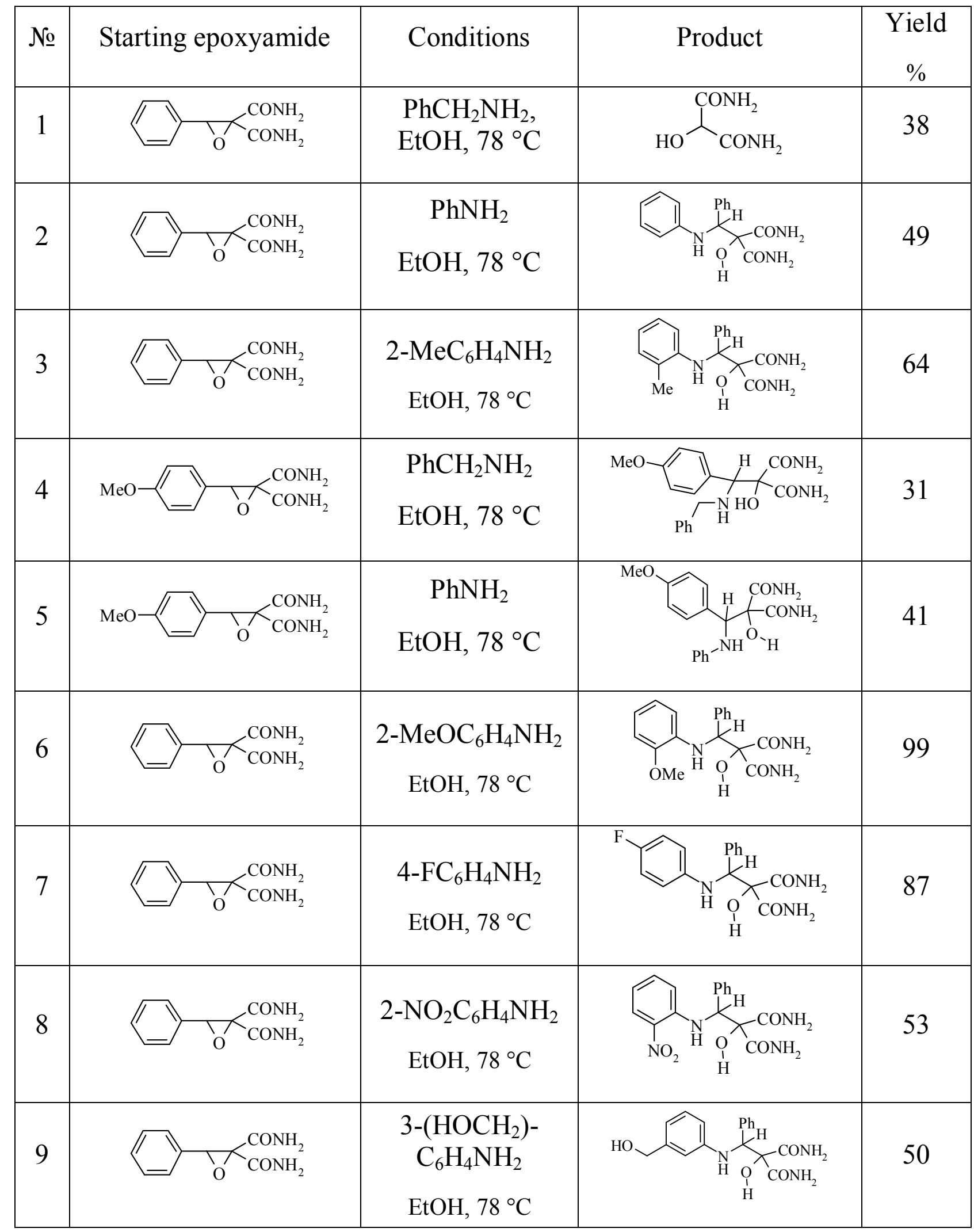


The structures of the compounds were studied in details by 2D NMR spectroscopy. Thus, the structure of tartronamide 10 (Figures 3-5) and $\beta$-amino- $\alpha-\mathrm{OH}-$ dicarboxamide 9a $(\mathrm{Ar}=\mathrm{Ph}, \mathrm{R}=\mathrm{Ph})$ (Fig. 6) was studied and unambiguously determined using a wide range of methods.

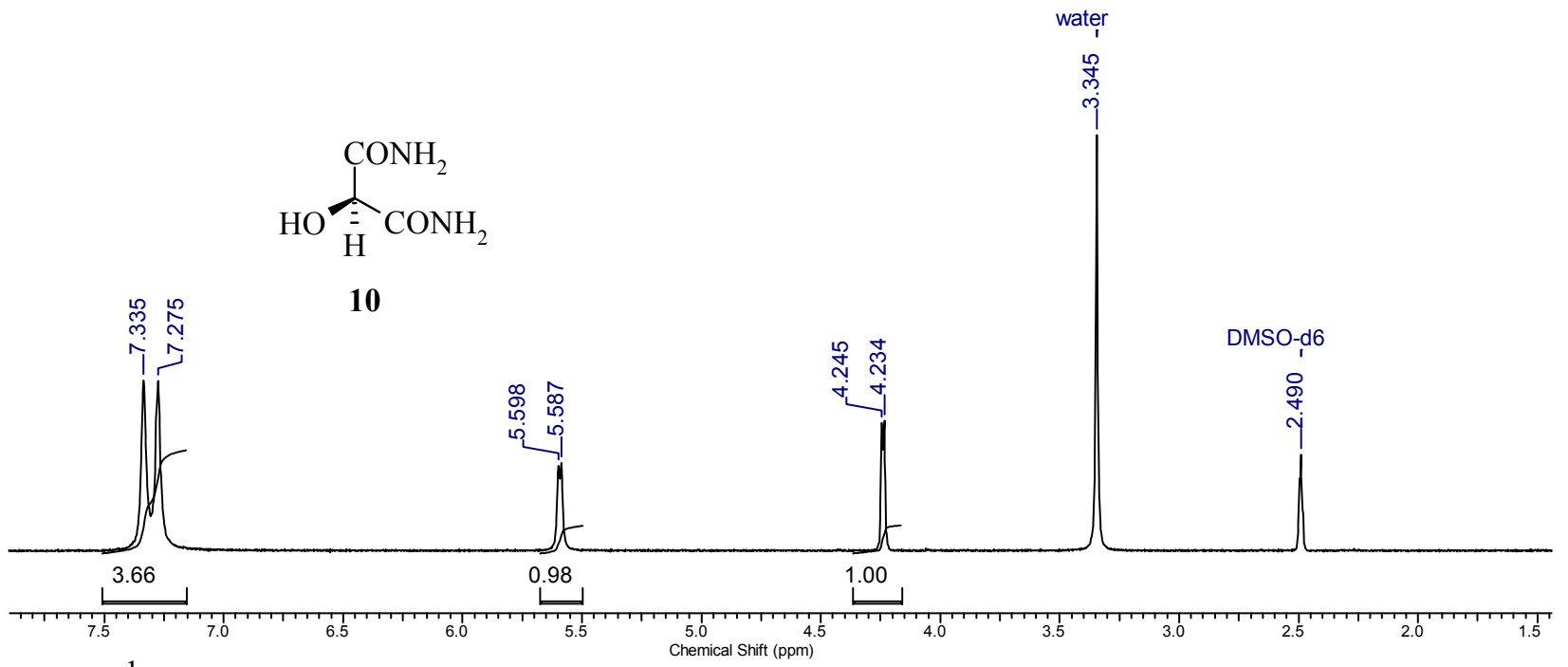

Fig. 3. ${ }^{1} \mathrm{H}$ NMR spectrum (400 MHz, DMSO-d 6 ) of tartronamide 10.

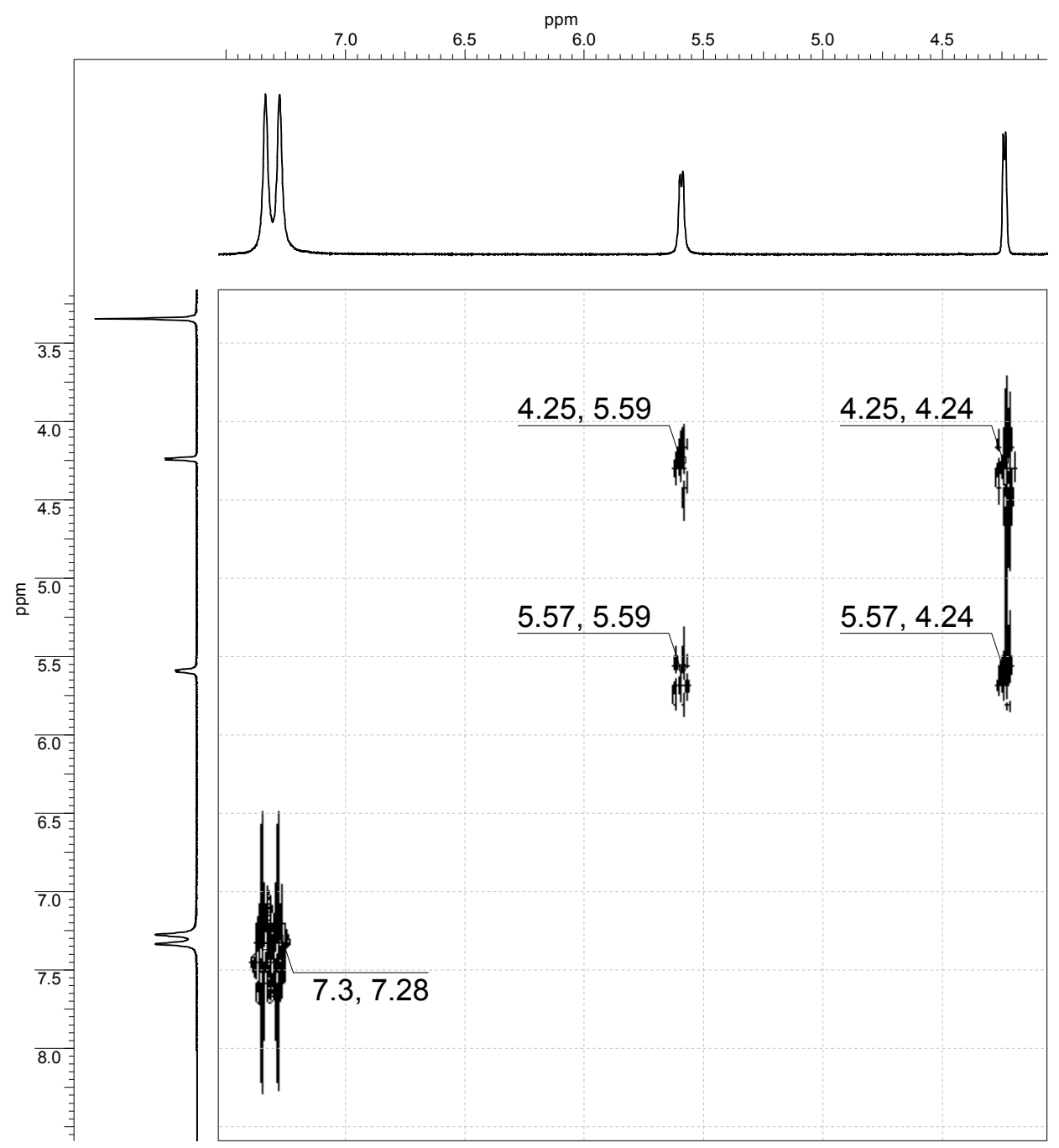

Fig. 4. COSY 2D NMR spectrum (400/400 MHz, DMSO-d $\left.{ }_{6}\right)$ of tartronamide 10. 


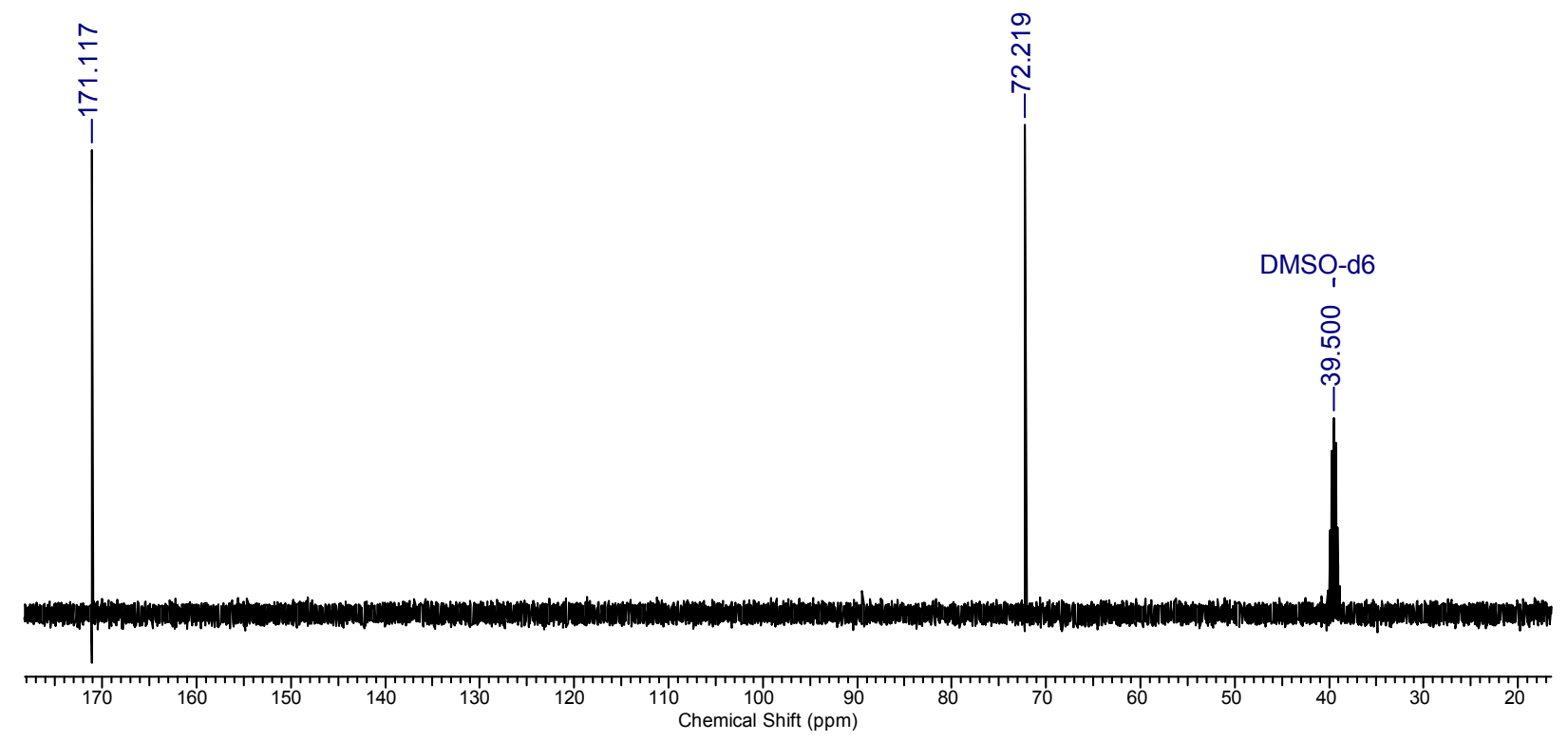

Fig. $5 .{ }^{13} \mathrm{C}$ NMR spectrum (100 MHz, DMSO-d ${ }_{6}$ ) of tartronamide $\mathbf{1 0}$.

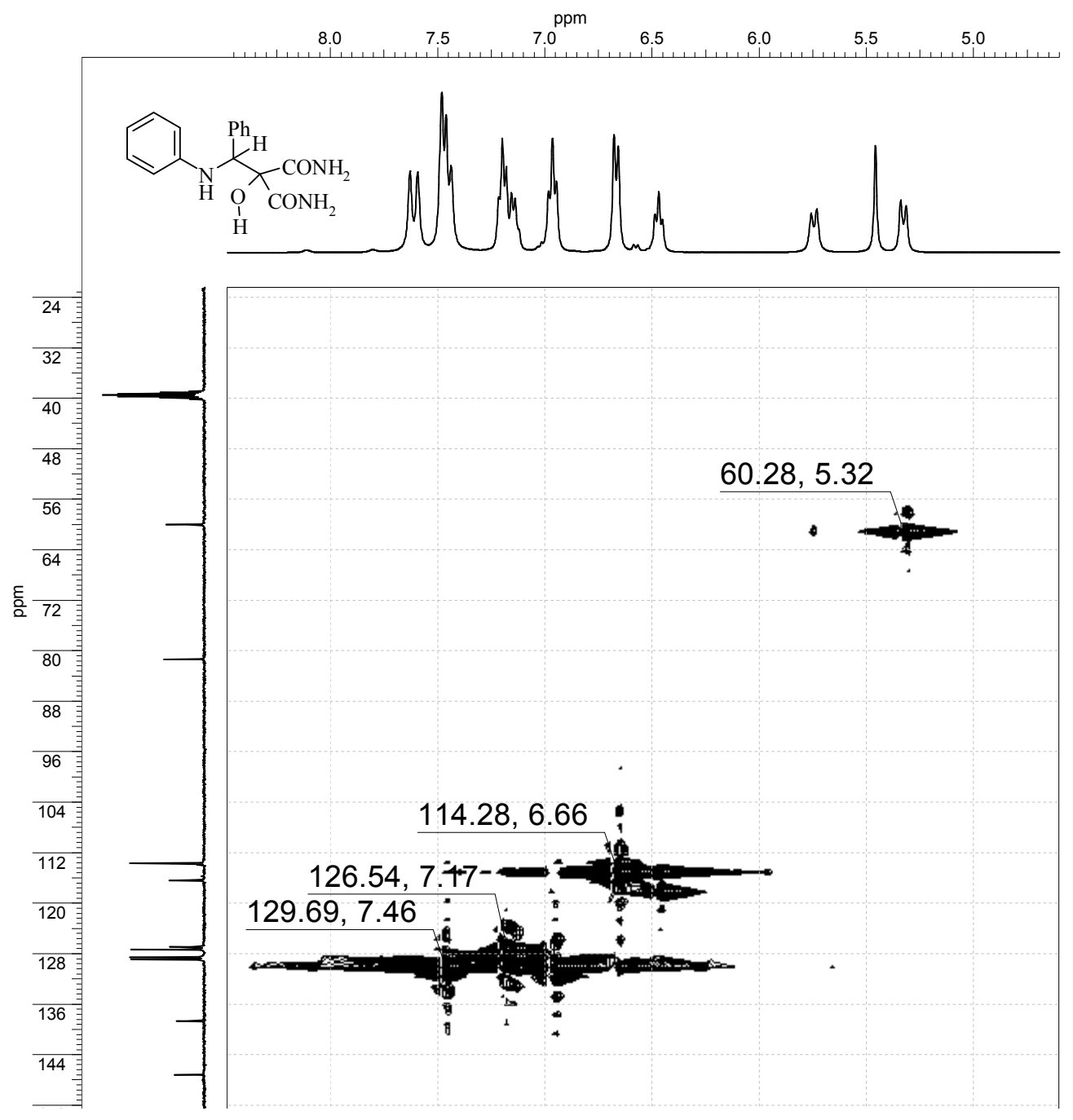

Fig. 6. HSQC 2D NMR spectrum $\left(100 / 400 \mathrm{MHz}, \mathrm{DMSO}-\mathrm{d}_{6}\right)$ of $\beta$-amino- $\alpha-$ hydroxydicarboxamide $9 \mathrm{a}(\mathrm{Ar}=\mathrm{Ph}, \mathrm{R}=\mathrm{Ph})$. 


\section{References}

1. Dryuk V.G., Kartsev V.G., Voytsekhovskaya M.A. Oxiranes - synthesis and biological activity. M: Bogorodsky Pechatnik, 1999, 528 pp. (in Russian).

2. Murray J.V., Cloke J.B. The Formation of Glycidamides by the Action of Hydrogen Peroxide on $\alpha, \beta$-Ethylenic Nitriles // JACS. 1934. Vol. 56. No.12. P. 2749-2751.

3. Payne G.B. Reactions of Hydrogen Peroxide. VIII. Oxidation of Isopropylidenemalono-nitrile and Ethyl Isopropylidenecyanoacetate // J. Org. Chem. 1961. Vol. 26. P. 663-668.

4. V. V. Dotsenko, S. G. Krivokolysko, E. B. Rusanov, A. V. Gutov, and V. P. Litvinov. Synthesis of 3-(4-chlorophenyl)oxirane-2,2-dicarboxamide // Russian Chemical Bulletin, Int. Ed., Vol. 56, No. 7, pp. 1470-1473, July, 2007. 